Çukurova Üniversitesi Mühendislik Mimarlık Fakültesi Dergisi, 33(3), ss. 237-244, Eylül 2018

Çukurova University Journal of the Faculty of Engineering and Architecture, 33(3), pp. 237-244, September 2018

\title{
CuZn40Pb2'nin Elektriksel İletkenliği Üzerine Aşırı Plastik Deformasyonun Etkisi
}

\author{
Hasan KAYA*1 \\ ${ }^{1}$ Kocaeli Üniversitesi, Asım Kocabıyık MYO, Makine ve Metal Teknolojileri Bölümü, Kocaeli
}

Geliş tarihi: $30.05 .2018 \quad$ Kabul tarihi: 15.10 .2018

$\ddot{\mathbf{O z}}$

$\mathrm{Bu}$ çalışmada, $\mathrm{CuZn} 40 \mathrm{~Pb} 2$ pirinç malzemesi hem ticari nitelikte hem de eşit kanal açısal presleme (EKAP) işlem metodu ile tek pas kullanılarak aşırı plastik deformasyonu oluşturularak elektriksel özellik üzerine mikroyapı ve mekanik özelliklerin etkisi incelenmiştir. Özellikle $\mathrm{Cu}$ bazlı malzemelerin elektriksel ve korozyon özelliklerinin iyi olduğu bilinmesine karşın tane boyutlarında elde edilebilecek küçülmelerin mekanik ve fiziksel özelliklerini nasıl etkilemiş olabileceği çalışmanın temelini oluşturmaktadır. Bilindiği üzere ticari özelliklerde pirinç alaşımları endüstriyel anlamda gemi sanayiinde, otomotiv sanayiinde ve diğer birçok endüstriyel alanda uygulama içerinde kullanılmaktadırlar. Bu kapsamda yapılan çalışma ile EKAP tekniği kullanılarak $\mathrm{CuZn40Pb2}$ malzemesi tane boyutları ufaltılmış, sertlik özelliklerinde \%34 artı̧̧ ve elektriksel özelliklerinde ise \%3 azalma göstermiştir.

Anahtar Kelimeler: Pirinç malzeme, Elektriksek iletkenlik, Aşırı plastik deformasyon, EKAP, Mekanik özellikler

\section{The Effect of Severe Plastic Deformation on the Electrical Conductivity of CuZn40Pb2}

\begin{abstract}
In this study, the effects of microstructure and mechanical properties on electrical properties of $\mathrm{CuZn} 40 \mathrm{~Pb} 2$ brass material were investigated by using both a commercial quality and an equal channel angular pressing (ECAP) process. Especially, although it is not known that the electrical and corrosion properties of Cu-based materials are good, it is the basis of studying how mechanical and physical properties of the size reductions may be affected. As is known, commercially available brass alloys are used industrially in the shipbuilding industry, the automotive industry and many other industrial applications. In this study, the grain size of $\mathrm{CuZn} 40 \mathrm{~Pb} 2$ material decreased and the hardness properties increased at $34 \%$ and electrical properties decreased at $3 \%$ with ECAP technique.
\end{abstract}

Keywords: Brass material, Electrical conductivity, Severe plastic deformation, ECAP, Mechanical properties

*Sorumlu yazar (Corresponding author): Hasan KAYA, hasan.kaya@kocaeli.edu.tr 


\section{GíRiș}

Bakır alaşımları içerisinde pirinç malzemeler, korozyon dayanımı, şekillendirilebilirlik kabiliyetleri ve mekanik özellikleri ile boru yapımında, valf imalatında ve bağlantı elemanı olarak kullanım alanlarına sahiptir. Tüm bu uygulama alanlarına ilaveten pirinç alaşımları elektronik parçalarda da son dönemlerde yaygın olarak kullanım göstermektedir [1-3]. Özellikle aşırı plastik deformasyon (APD) işlem teknikleri kullanılarak elde edilen ultra ince taneli (UIT) yapılı malzemeler, bakır bazlı malzemelerin mekanik özelliklerinin geliştirilmesinin [4-10] yanı sıra elektriksel iletkenliğin önemli olduğu alanlarda da kullanım gelişimlerine katkıda bulunmuştur [4,7,11-13]. APD tekniklerinin içerisinde EKAP tekniği en etkili metot olarak tanımlanmaktadır [14-20]. EKAP özellikle, numune boyutlarını değiştirmeksizin kütlesel yönlenme ve burulma dayanımı ile UIT yapısının elde edilmesini sağlamaktadır [14-25].

$\mathrm{Bu}$ çalışmada ticari $\mathrm{CuZn} 40 \mathrm{~Pb} 2$ ile EKAP işlem tekniği kullanılarak üretilen malzemelerin mikroyapı ve mekanik özelliklerinin kıyaslanması ve elektriksel direnç özellikleri arasındaki değişim incelenmiştir.

\section{MATERYAL VE METOT}

Bu çalışmada, endüstriyel anlamda kullanımı olan ve temin edilebilen Çizelge 1' de elemental içeriği verilen $\mathrm{CuZn} 40 \mathrm{~Pb} 2$ pirinç malzemesi kullanılmıştır. Pirinç malzeme, EKAP yapabilmek amaciyla $20 \mathrm{~mm}$ çap ve $55 \mathrm{~mm}$ uzunluğunda tornalanmıştır. EKAP işlemi $210 \quad{ }^{\circ} \mathrm{C}$ kalıp sıcaklığında, $90^{\circ}$ kalıp açısında $\mathrm{C}$ işlem rotası kullanılarak yapılmıştır. İşlem esnasında 120 ton kapasiteli hidrolik preste $1,5 \mathrm{~mm} / \mathrm{sn}$ strok ilerleme hızı kullanılmıştır. Mikroyapı incelemeleri için hazırlanan numuneler $25 \mathrm{~g} \mathrm{FeCl}_{3}-50 \mathrm{ml} \mathrm{HCl}-$ $100 \mathrm{ml} \quad \mathrm{H}_{2} \mathrm{O}$ çözeltisi dağlayıcı olarak kullanılmıştır. Sirasıyla 200-400-600-800-1000$1200 \mu \mathrm{m}$ zimpara ve son olarak elmas solüsyon parlatıcı ile standart metalografik işlem teknikleri kullanılmıştır. Mikroyapı incelemeleri için optik görüntülerinde, Zeiss Axiotech ve Olympus BX41M-LED 1ş1k mikroskobu, tarama elektron mikroskobu ve EDS görüntüleri için ise Jeol JSM 6060 model tarama elektron mikroskobu (SEM) cihazı kullanılmıştır. Sertlik ölçümleri için BMS Microbul 1000DN model mikrosertlik cihazı kullanılarak sertlik ölçümleri $\mathrm{HV}_{0.1}$ olarak ölçülmüştür.

Çizelge 1. CuZn40Pb2 alaşımının kimyasal analizi

\begin{tabular}{|c|c|c|c|c|c|c|c|}
\hline Alaşım & \multicolumn{7}{|c|}{ Element (Kütle \%) } \\
\hline \multirow{2}{*}{$\mathrm{CuZn40Pb2}$} & $\mathrm{Zn}$ & $\mathrm{Pb}$ & $\mathrm{Cu}$ & $\mathrm{Fe}$ & $\mathrm{Sn}$ & $\mathrm{Ni}$ & $\mathrm{Al}$ \\
\cline { 2 - 8 } & 39,5 & 2,38 & 57,4 & 0,28 & 0,29 & 0,10 & 0,03 \\
\hline
\end{tabular}

Çalışma kapsamında özel olarak manuel rotasyon problemini ortadan kaldırmak ve işlem süresini kısaltmak adına yeni bir tasarım olan Hexa ECAP kalıbı kullanılmıştır (Şekil 1).

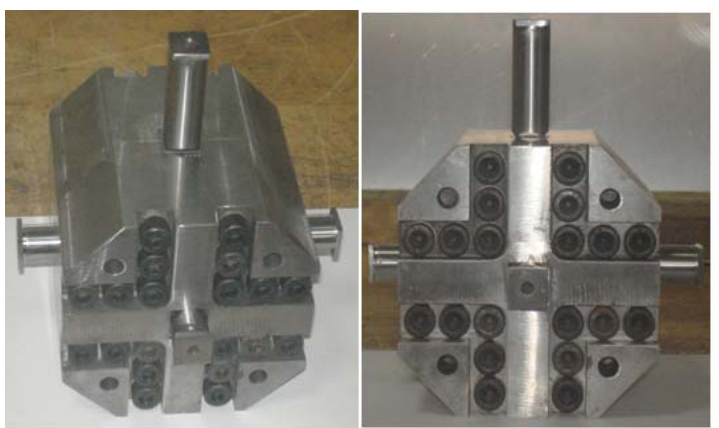

Şekil 1. Deneysel çalışmalarda kullanılan Hexa EKAP kalıbı $[14,16]$

Başlangıç ve EKAP yapılan malzemelerin elektriksel iletkenlik testleri Fischer marka
SMP350 cihazı kullanılarak yapılmıştır. İletkenlik ölçme işleminde DIN EN 2004-1 ve 
ASTM E 1004 standartlarına uygun olarak faz yapısına duyarlı Eddy akımı yöntemi, oda sıcaklığında, $60 \mathrm{kHz}$ ölçme frekansı uygulanarak

\section{DENEYSEL SONUÇLAR VE TARTIŞMA}

\subsection{Mikroyapı Karakterizasyonu ve Mekanik Özellikler}

Başlangıç malzemesi ve EKAP yapılmış malzemenin optik mikroskop görüntüleri Şekil 2'de verilmiştir. Optik mikroskop görüntüleri incelendiğinde EKAP yapılmış numune de ki tane boyutlarının merkeze doğru olan kısımlarında başlangıç malzemesine oranla daha küçük olduğu

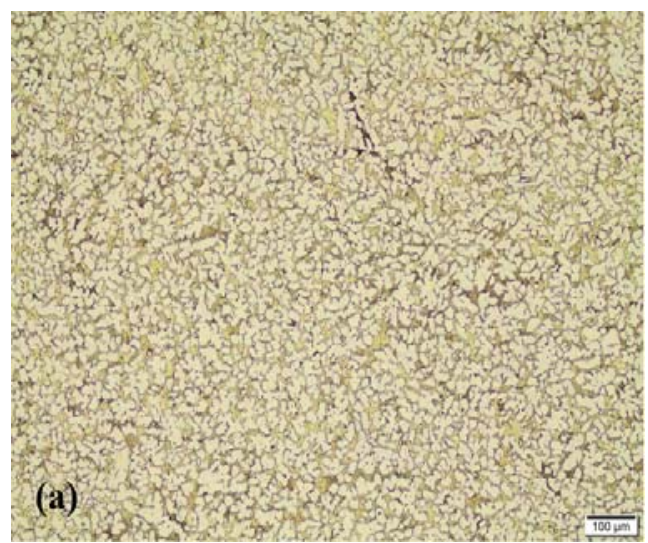
gerçekleştirilmiştir.

görülmektedir. Aşırı plastik deformasyon yöntemi olan EKAP işlemi sonucunda elde edilen malzemelerin mikroyapıları incelendiğinde ise, kesit boyunca yönlenmenin neredeyse yok denecek kadar az olduğu, ancak köşelerde çok yüksek miktarlarda yönlenme olduğu (Şekil 2.b) belirgin olarak görülmektedir. İşlem tekniğinin uygulandığı düşük sıcaklık ve başlangıç numunesinin var olan yüksek sertlik değeri ile dislokasyonlar sebebi ile yer yer çatlaklar görünmektedir. EKAP işlem tekniği, malzemelerin mikroyapısındaki tanelerin boyutlarını ufaltırken, yönlenmesini de sağlamaktadır. Yönlenmenin etkisi EKAP geçiş sayısının artışı ile birlikte mikroyapıda tane boyutlarının küçülmesine etki etmektedir $[14,26,27]$.

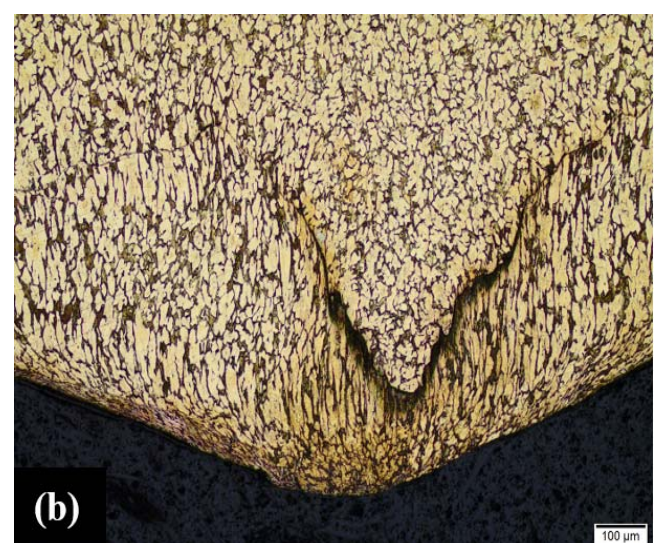

Şekil 2. Optik mikroskop görüntüleri; (a) Başlangıç malzemesi, (b) EKAP 1 Pas yapılmıș malzeme

Boyutsal değişimden kaynaklanan daha küçük tane yapısı ise malzemenin sertlik artışına etki etmektedir. Yapılan çalışmalar ile kıyaslandığında [14,18,21,28,29] Çizelge 2'de ölçülen sertlik değerlerinin de aynı özellikleri gösterdiği anlaşılmaktadır. Yapılan deneysel işlemlerin ardından ölçülen sertlik değerlerinde EKAP yapılan malzemenin sertliğinin, başlangıç malzemesine göre yaklaşık $44 \mathrm{HV}_{0.1}$ 'lik artış gösterdiği ölçülmüştür.

Çizelge 2. Ölçülen sertlik değerleri

\begin{tabular}{|l|c|}
\hline Malzeme & Sertlik Değeri $\left(\mathbf{H V}_{\mathbf{0}, \mathbf{1}}\right)$ \\
\hline Başlangıç Malzemesi & 129,55 \\
\hline EKAP 1 Pas Malzemesi & 173,2 \\
\hline
\end{tabular}

Deneysel çalışmalarda kullanılan başlangıç malzemesinin ve EKAP işlemi sonrasında elde edilen pirinç malzemesine ait SEM mikroyapı görüntüleri Şekil 3'de verilmiştir. SEM mikroyapı görüntüleri. Optik mikroskop görüntülerinde olduğu gibi aşırı plastik deformasyonun etkisini, başlangıç malzemesi ile arasındaki tane boyutları ve deformasyon yönlenmeleri ile farklarını göstermektedir. Alınan görüntülerde başlangıç numunesi için (Şekil 3.a) dentritik ve eşeksenel tane yapılarının oluşturduğu bir mikroyapı görülürken EKAP yapılmış malzeme de (Şekil 3.b) ise yönlenmenin olduğu sütunsal ve pankek bir mikroyapı oluştuğu görülmektedir. EKAP yapılmış çalışmalar incelendiğinde, yapılan çalışmada 
olduğu gibi tane yapısındaki incelmeler, deformasyon çizgileri ve belirgin yönlenmelerin olduğu belirtilmektedir [14,27].
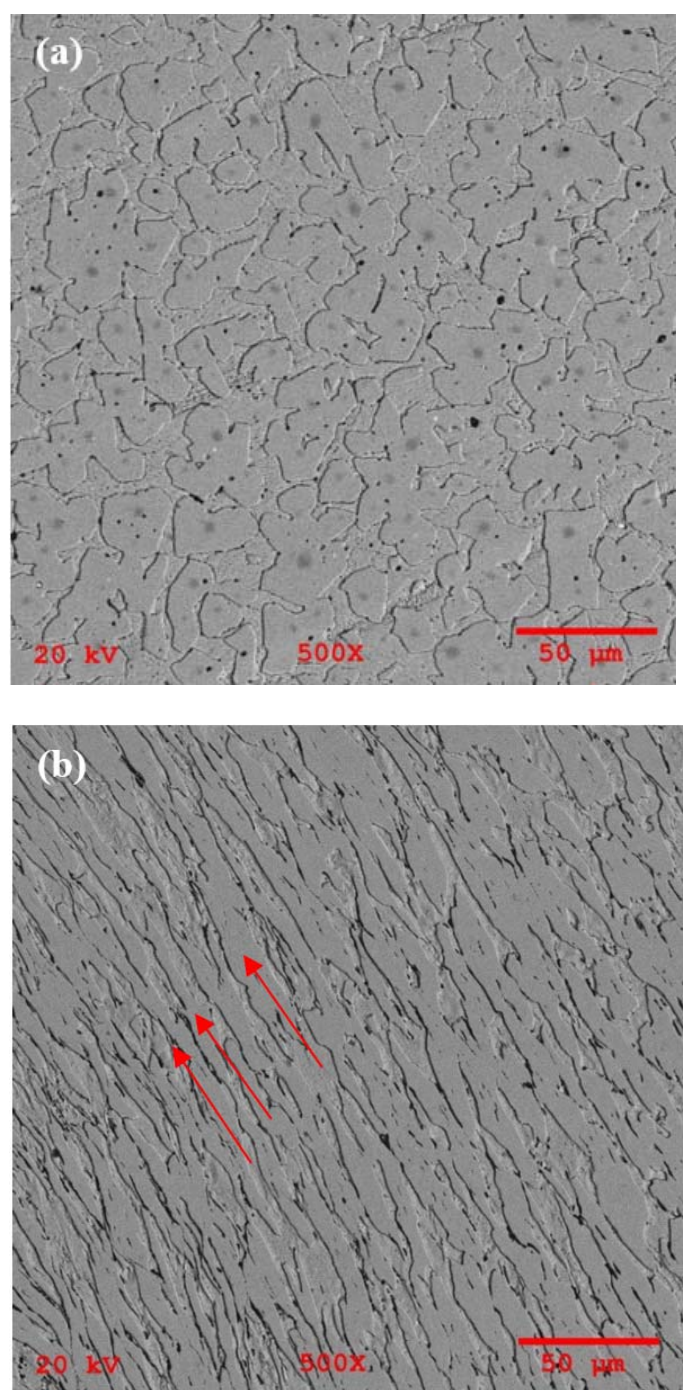

Şekil 3. Tarama elektron mikroskop (SEM) görüntüleri; (a) Başlangıç malzemesi, (b) EKAP 1 Pas yapılmış malzeme

Şekil 4'de başlangıç malzemesi ve EKAP yapılmış malzemelerin EDS analizleri verilmiştir. Başlangıç malzeme mikroyapısı incelendiğinde $\alpha$-Cu'ca, $\beta$ Zn'ce zengin bir çift fazlı yapı dikkati çekmektedir. Küresel ve koyu renkli olan bölgeler $\mathrm{Pb}$ taneciklerini göstermektedir. Özellikle EKAP numuneleri incelendiğinde, başlangıç malzemesine kıyasla plastik deformasyon akışı görülmektedir. Beta çinko nedeni ile kafes yapısı plastik akışa uygun olmamasına karşın yine de belirli bir doğrultuda uzama göstermiştir.
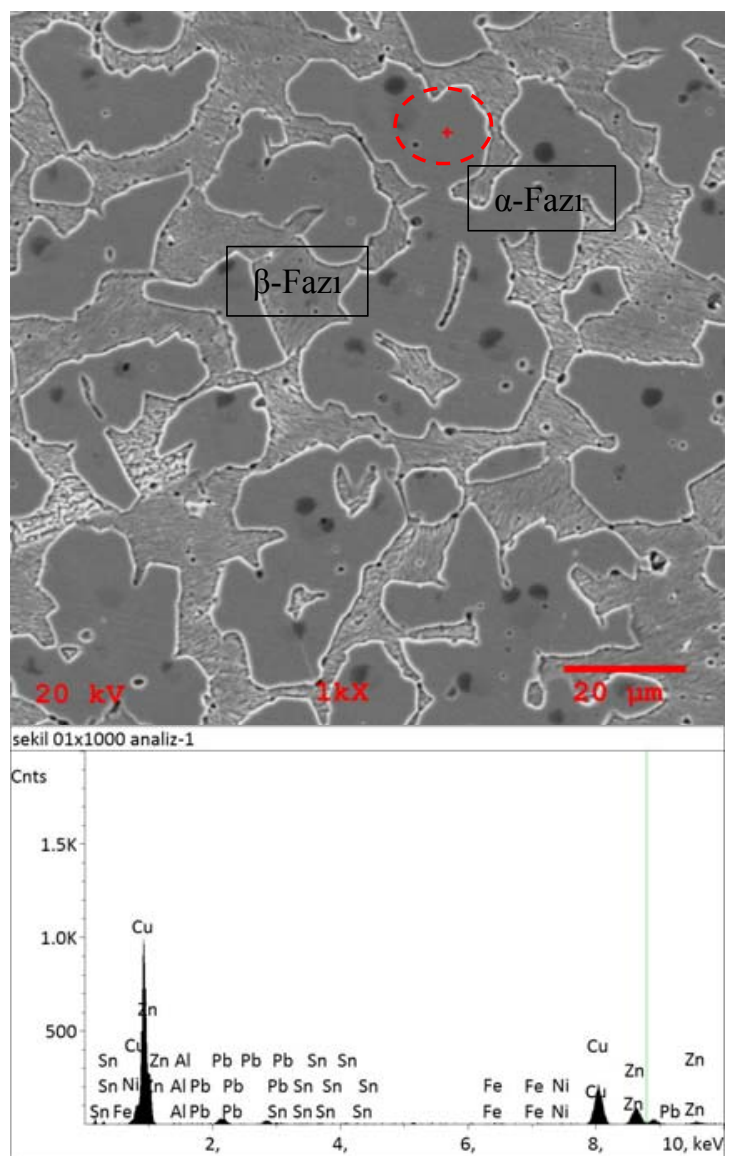

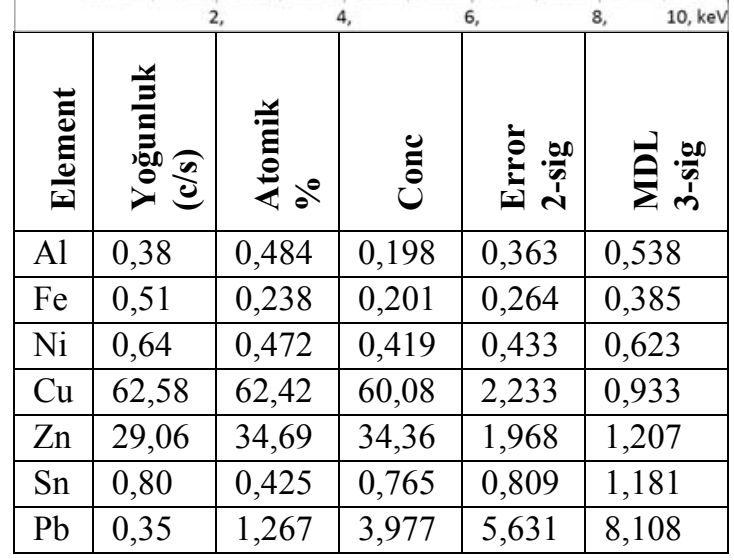

(a) 


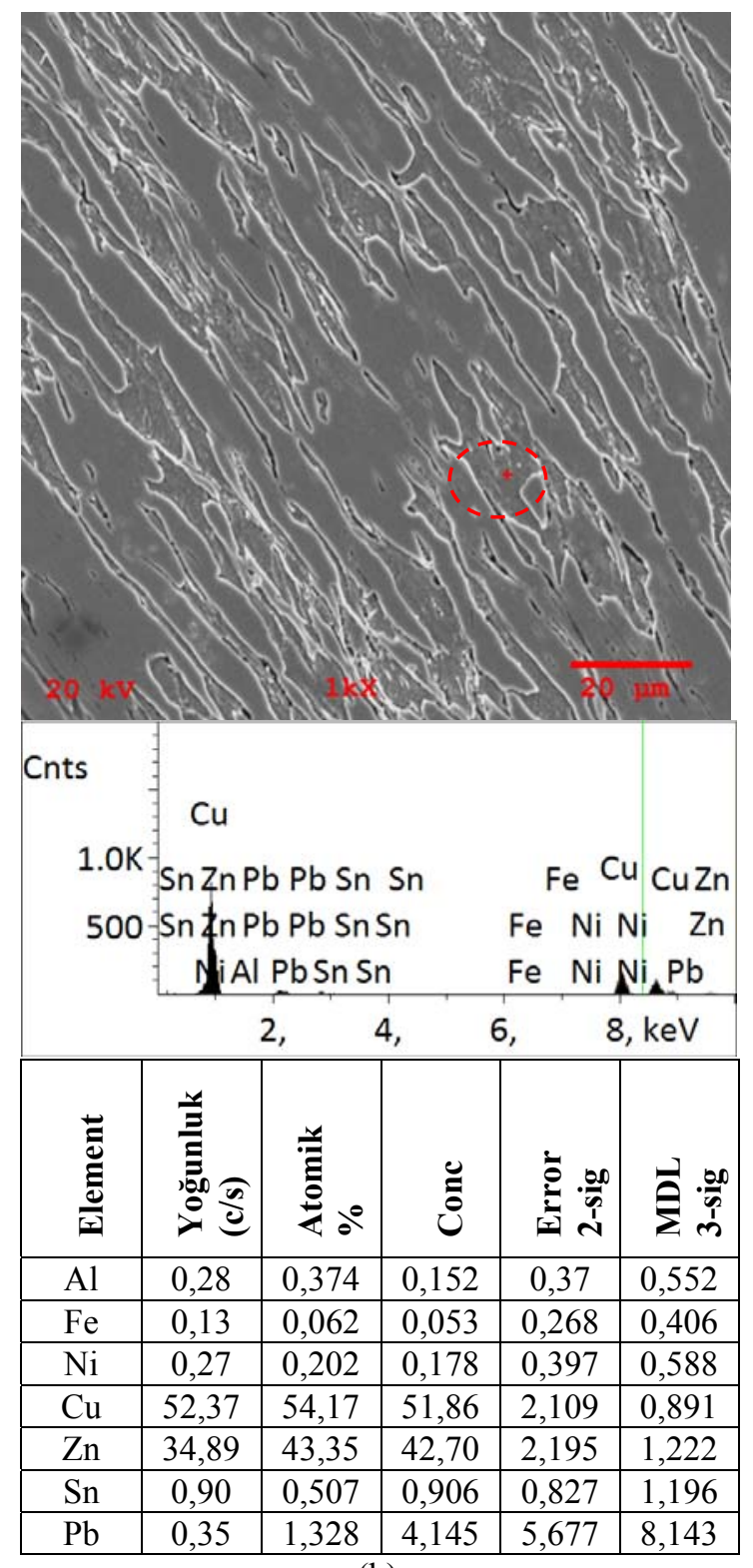

(b)

Şekil 4. Tarama Elektron Mikroskobu EDS analizi (a) Başlangıç malzemesi, (b) EKAP 1 Pas yapılmış malzeme

\subsection{Elektriksel İletkenlik}

Başlangıç malzemesi ve EKAP yapılmış malzemelerin elektriksel iletkenlik ölçümleri için $60 \mathrm{kHz}$ ölçüm frekansı kullanılmıştır. Ölçme işlemi her bir malzeme için dörder kez tekrarlanmıştır. Elde edilen sonuçlara ait Şekil 5'de verilen grafik incelendiğinde, başlangıç malzemesinin iletkenliğinin EKAP yapılmış malzemeye göre daha yüksek bir değere sahip olduğu görülmektedir. Metalik malzemelerde dislokasyonlar iletkenliğin azalmasına sebep olmaktadır [30]. Malzeme içerisindeki dislokasyon miktarının yoğunluğu ise alaşımın özelliğine, sicaklığa, uygulanan deformasyon miktarına ve özelliğine göre de değişkenlik göstermekte olup Mtthiesen teoremine göre açıklanabilmektedir. Matthiessen teoremine [31-33] göre, $\mathrm{P}_{\text {Toplam }}=\mathrm{P}_{1}+$ $\mathrm{P}_{\mathrm{i}}+\mathrm{P}_{\mathrm{d}}$ eşitliğinde; $\mathrm{P}_{\text {Toplam; }}$ elektriksel özdirenç toplamını, $\mathrm{P}_{1}$; 1sıl özdirenç, $\mathrm{P}_{\mathrm{i}}$; impurite elementler özdirenci ve $\mathrm{P}_{\mathrm{d}}$ ise dislokasyon-deformasyonun sebep olduğu özdirenci göstermektedir. Belirtilen eşitliğe göre toplam değer malzemenin özdirenci ile ilişikilendirilmektedir. Diğer bir deyişle deformasyon miktarındaki artış ile birlikte malzemenin özdirenci artmakta (iletkenliği azalmakta)'dır. Elektriksel iletkenlik üzerine yapılan çalışmalar değerlendirildiğinde [30-33] EKAP yapılmış olan malzemenin sertlik değerlerinde aşırı plastik deformasyon etkisi ile başlangıç malzemesine göre yaklaşık \%34 artış oluşturulmuştur. Ancak sertlikte elde edilen yüzdelikteki artış, elektriksel iletkenlikte daha düşük değerlerde kalmıştır. Bunun da sebebinin deformasyon miktarında önemli oranda artış olmasına karşın EKAP tekniğine bağlı olarak tane yapısının üniform bir yapı sergilemesi ve dislokayon miktarındaki azalma olarak düşünülmektedir.

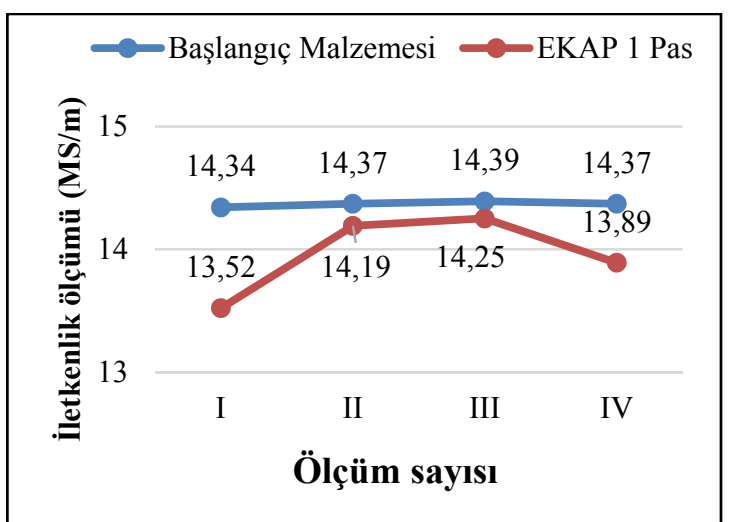

Şekil 5. Elektriksel iletkenlik ölçüm değerleri 


\section{SONUÇLAR}

CuZn40Pb2'nin elektriksel iletkenliği üzerine aşırı plastik deformasyonun etkisi başlıklı çalışma incelendiğinde;

- EKAP tekniği kullanılarak APD işlemi gerçekleştirilmiştir.

- EKAP uygulanmış malzemenin sertlik değeri, başlangıç malzemesine göre \%34 daha yüksek olarak elde edilmiştir.

- Mikroyapı sonuçları incelendiğinde, başlangıç malzemesinin tane yapılarının kaba ve eşeksenel yapılardan oluştuğu dikkati çekmektedir. EKAP yapılmış malzemelerde ise ince tane yapıları ve yönlenmelerin olduğu görülmektedir.

- Yapılan elektriksel iletkenlik ölçümlerinde alınan sertlik sonuçlarının aksine, aşırı plastik deformasyonun etkisi ile EKAP yapılmış malzemenin elektriksel direncinin daha yüksek olduğu diğer bir deyişle iletkenliğinin azaldığı ölçülmüştür.

\section{KAYNAKLAR}

1. Kim, H.S., Kim, W.Y., Song, K.H., 2012. Effect of Post-heat-treatment in ECAP Prpcessed $\mathrm{Cu}-40 \% \mathrm{Zn}$ Brass, Journal of Alloys and Compounds, 536, 200-203.

2. Xia, Z., Szklarska-Smialowska, Z., 1990. Pitting of Admiralty Brass, Corrosion, 46, 85-88.

3. Brooks, C.R., 1982. Heat Treatment, Structure and Properties of Nonferrous Alloy, American Society for Metals, Metals Park, Ohio, 139-142.

4. Straumal, P.B., Wegner, M., Shangina, D.V., Kogtenkova, O.A., Kilmametov, A., Divinski, S.V., Dobatkin, S.V., Wilde, G., 2017. Diffusion of $63 \mathrm{Ni}$ in Severely Deformed Ultrafine Grained Cu-based Alloys, Scripta Materialia, 127, 141-145.

5. Chinh, N.Q., Valiev, R.Z., Sauvage, X., Varga, G., Havancsák, K., Kawasaki, M., Straumal, B.B., Langdon, T.G., 2014. Grain Boundary
Phenomena in an Ultrafine-grained Al-Zn Alloy with Improved Mechanical Behavior for Micro-devices, Advanced Engineering Materials, 16, 1000-1009.

6. Purcek, G., Yanar, H., Saray, O., Karaman, I., Maier, H.J., 2014. Effect of Precipitation on Mechanical and Wear Properties of Ultrafinegrained Cu-Cr-Zr Alloy, Wear 311, 149-158.

7. Islamgaliev, R.K., Nesterov, K.M., Bourgon, J., Champion, Y., Valiev, R.Z., 2014. Nanostructured $\mathrm{Cu}-\mathrm{Cr}$ Alloy with High Strength and Electrical Conductivity, Journal of Applied Physics, 115, 194-301.

8. Xu, C.Z., Wang, Q.J., Zheng, M.S., Zhu, J.W., Li, J.D., Huang, M.Q., Jia, Q.M., Du, Z.Z., 2007. Microstructure and Properties of UltraFine Grain $\mathrm{Cu}-\mathrm{Cr}$ Alloy Prepared by Equalchannel Angular Pressing, Materials Science and Engineering A, 459, 303-308.

9. Shangina, D., Maksimenkova, Y., Bochvar, N., Serebryany, V.N., Raab, G., Vinogradov, A., Skrotzki, W., Dobatkin, S., 2014. Structure and Properties of CuAlloys Alloying with $\mathrm{Cr}$ and Hf After Equal Channel Angular Pressing, Advanced Materials Research, 922, 651-656.

10. Wang, Q.J., Xu, C.Z., Zheng, M.S., Zhu, J.W., Du, Z.Z., 2008. Fatigue Crack İnitiation life Prediction of Ultra-fine Grain ChromiumBronze Prepared by Equal-channel Angular Pressing, Materials Science and Engineering A, 496, 434-438.

11. Dobatkin, S.V., Shangina, D.V., Bochvar, N.R., 2015. Aging Processes in Ultrafinegrained Low-alloyed Bronzes Subjected to Equal Channel Angular Pressing, Advanced Engineering Materials, 17, 1862-1868.

12. Mishnev, R., Shakhova, I., Belyakov, A., Kaibyshev, R., 2015. Deformation Microstructures, Strengthening Mechanisms, and Electrical Conductivity in a $\mathrm{Cu}-\mathrm{Cr}-\mathrm{Zr}$ alloy, Materials Science and Engineering A, 629, 29-40.

13. Shangina, D.V., Gubicza, J., Dodony, E., Bochvar, N.R., Straumal, P.B., Tabachkova, N.Y., Dobatkin, S.V., 2014. Improvement of Strength and Conductivity in Cu-alloys with the Application of High Pressure Torsion and 
Subsequent Heat-treatments, Journal of Materials Science, 49, 6674-6681.

14. Kaya, H., Ucar, M., 2016. The Effect of Mechanical Properties on Fatigue Behavior of Ecaped AA7075, High Temperature Materials and Processes, 35(3), 225-234.

15. Horita, Z., Fujinami, T., Langdon, T.G., 2001. The Potential for Scaling ECAP: Effect of Sample Size on Grain Refinement and Mechanical Properties, Materials Science and Engineering A, 318, 34-41.

16. Kaya, H., Ucar, M., Cengiz, A., Samur, R., Ozyurek, D. Caliskan, A., 2014. Novel Moulding Technigue for ECAP Process and Effects on Hardness of AA7075, Mechanika, 20, 5-10.

17. Kim, W.J., Chung, C.S., Ma, D.S., Hong, S.I., Kim, H.K., 2003. Optimization of Strength and Ductility of 2024 Al by Equal Channel Angular Pressing (ECAP) and Post-ECAP Aging, Scripta Materialia, 49, 333-338.

18. Segal, V.M., 1995. Materials Processing by Simple Shear, Materials Science and Engineering A, 197, 157-164.

19. Tolaminejad, B., Dehghani, K., 2012. Microstructural Characterization and Mechanical Properties of Nanostructured AA1070 Aluminum After Equal Channel Angular Extrusion, Journal of Materials and Design, 34, 285-292.

20.Zhu, Y.T., Lowe, T.C., 2000. Observations and Issues on Mechanisms of Grain Refinement During ECAP Process, Materials Science and Engineering A, 291, 46-53.

21. Das, P., Jayaganthan, R., Chowdhury, T., Singh, I.V., 2011. Fatigue Behaviour and Crack Growth Rate of Cryorolled Al 7075 Alloy, Materials Science and Engineering A, 528, 7124-7132.

22. Ferrasse, S., Segal, S.M. 1997. Microstructure and Properties of Copper and Aluminum Alloy 3003 Heavily Worked by Equal Channel Angular Extrusion, Metal Materials Transactions A, 28, 1047-1057.

23. Horita, Z., Fujinami, T., 2000. Equal-channel Angular Pressing of Commercial Aluminum Alloys: Grain Refinement, Thermal Stability and Tensile Properties, Metall Materials Transactions A, 31, 691-701.

24. Semiatin, S.L., Berbon, P.B., Langdon, T.G., 2001. Deformation Heating and its Effect on Grain Size Evolution During Equal Channel Angular Extrusion, Scripta Materialia, 44, 135-140.

25. Nakashima, K., Horita, Z., Nemoto, M., Langdon, T.G., 2000. Development of a MultiPass Facility for Equal-channel. Angular Pressing to High Total Strains, Materials Science and Engineering A, 281, 82-87.

26. Tong, L.B., Zheng, M.Y., Hu, X.S., Wu, K., Xu, S.W., Kamado, S., Kojima, Y., 2010. Influence of ECAP Routes on Microstructure and Mechanical Properties of $\mathrm{Mg}-\mathrm{Zn}-\mathrm{Ca}$ alloy, Mater. Sci. Eng. A, 527, 4250-4256.

27. Kim, I., Kim, J., Shin, D.H., Lee, C.S., Hwang, S.K., 2003. Effects of Equal Channel Angular Pressing Temperature on Deformation Structures of Pure Ti, Materials Science and Engineering A, 342, 302-310.

28. Lapovok, R., Thomson, P.F., Cottam, R., Estrin, Y., 2005. Processing Routes Leading to Superplastic Behaviour of Magnesium Alloy ZK60, Materials Science and Engineering A, 410-411, 390-393.

29. Torre, F.D., Lapovok, R., Sandlin, J., Thomson, P.F., Davies, C.H.J., Pereloma, E.V., 2004. Microstructures and Properties of Copper Processed by Equal Channel Angular Extrusion for 1-16 Passes, Acta Materialia, 52, 4819-4832.

30. Abbas, S.F., Seo, S., Park. K., Kim, B., 2017. Effect of Grain Size on the Electrical Conductivity of Copper-iron Alloys, Journal of Alloys and Compounds, 720, 8-16.

31. Majchrowicz, K., Pakiela, Z., Chrominski, W., Kulczyk, M., 2018. Enhanced Strength and Electrical Conductivity of Ultrafine-grained Al-Mg-Si Alloy Processed by Hydrostatic Extrusion, Materials Characterization, 135, 104-114.

32. Atapek, Ş.H., Klinski-Wetzel, K., Heilmaier, M., 2012. Effect of Microstructure on the Electrical Conductivity of Cast and Aged CuNiSiCr Alloy, III. İleri Teknolojiler Çalıştayı, Bildiriler Kitabı, 433-443. 
33. Lipinska, M., Bazarnik, P., Lewandowska, M., 2016. The Influence of Severe Plastic Deformation Processes on Electrical Conductivity of Commercially Pure Aluminium and 5483 Aluminium Alloy, Archives of Civil and Mechanical Engineering, $16,717-723$. 